\title{
Mechanical Characterization of High Density Polyethylene 6063 Aluminium
}

\author{
R.T. Oluyori, E.I. Dongo and I.M. Momoh \\ Department of Metallurgy, Kogi State Polytechnic, Lokoja, Nigeria.
}

\begin{abstract}
This work investigated the effects of High-Density Polyethylene (HDPE) on the mechanical properties of 6063 aluminum. This was with a view to determine the impact of the HDPE on the tensile and hardness properties of 6063 aluminum. Two separate samples of 6063 aluminum were produced and designated $A$ and B for 0 and $5 \%$ HDPE respectively. Three test pieces were cut from each sample and prepared for tensile and hardness measurement. The micrographs of the samples were also prepared. The results obtained showed that sample B exhibited higher strength in comparison to sample A. A significant difference was also observed in the hardness in both specimens. The photomicrograph shows that there was segregation of the HDPE towards the grain boundaries thus introducing discontinuity in the grain boundaries.
\end{abstract}

Keywords: 6063 Aluminum, High Density Polyethylene, Microhardness, Tensile Properties.

\section{Introduction}

Aluminum is one of the most important materials that have find its broader use in the domestic and industrial sector. This versatility has been attributed to its reasonably high strength, light weight, machinability, resistant to corrosion attack, viability and affordability $[3,4]$. These excellent properties serves as an impetus to its versatility $[5,6,7]$.

Previous research on the improvement of mechanical properties has been focused on heat treatment, precipitation, age hardening [8] and reinforced with industrial and inorganic materials to enhanced its properties $[9,10,11,12]$.

Polyethylene (PE) is being increasingly used in many industrial and biomedical applications. Its outstanding features such as regular chain structure, combination of low cost and low energy demand for processing, excellent biocompatibility, and good mechanical properties make PE expand its application continuously $[13,14]$. The superiority of PE products over metal products is attributed to their light weight, high corrosion resistance, and low costs. However, there are some drawbacks with Polyethylene including low environmental stress cracking resistance, low creep resistance, and poor compatibility with various additives which restricted its use for cretin purposes $[15,16]$. Therefore, there have been many attempts to improve the properties of polyethylene by blending it with organic or inorganic materials [15 - 19].

A density of $\geq 0.941 \mathrm{~g} / \mathrm{cm}$ defines High-Density Polyethylene (HDPE). It has a low degree of branching and thus account for its strong intermolecular forces and tensile strength [2]. The mechanical properties of a material which is used to assess and determine the applicability of any material [1] is a basis for this research. To this effect, this work focuses on the study of the effects of HDPE on the mechanical properties of 6063 Aluminium.

\subsection{Mould Preparation}

\section{Experimental Work}

Plastic cylindrical pattern of diameter $20 \mathrm{~mm}$ by $120 \mathrm{~mm}$ length was used to prepare the sand mould. The mould was prepared using cope and drag in which prepared moulding sand was rammed round the pattern, this was to create an impression called the mould in which the melt would be poured after the withdrawal of the pattern from the sand.

\subsection{Charge Preparation, Melting and Casting}

6063 Aluminium was selected to be the base metal used for the experiment. The base metal was cast without any addition and was designated A. A second casting having $95 \%$ by weight of the 6063 aluminium alloy and $5 \%$ by weight of high density polyethylene (HDPE). The aluminium alloy was melted and superheated to a pouring temperature of $690^{\circ} \mathrm{C}$, removed from the furnace and poured into the prepared mould to form cast. The cast was designated B. The two cast were allowed to solidify in the mould to room temperature. They were subsequently knocked out, cleaned and fettled. 


\subsection{Metallographic Preparation}

Microstructural examination of specimens was performed using daheng software driven optical microscope. Prior to this, the specimens were metallographically prepared by grinding using a series of emery papers of grit sizes ranging from $60-1200 \mu \mathrm{m}$; while fine polishing was performed using polycrystalline diamond suspension of particle sizes $2.0 \mu \mathrm{m}$ with ethanol solvent. The specimens were etched with $0.5 \% \mathrm{HF}$ solution by swabbing before observation with the optical microscope.

\subsection{Mechanical properties preparation}

A room temperature uniaxial tension tests were performed on round tensile samples machined from the prepared composites with average dimensions of $5 \mathrm{~mm}$ diameter and $30 \mathrm{~mm}$ gauge length. The test was performed using an software driven electronic tensiometer operated at a constant cross head speed of $1 \mathrm{~mm} / \mathrm{s}$. The specimen dimension specifications and the test procedure adopted were in conformity with ASTM E8M 91 standards $[8,10]$. Four repeat tests were performed for composite composition to guarantee reliability of the data generated. The tensile properties evaluated from the stress-strain curves developed from the tension test are - the ultimate tensile strength $\left(\sigma_{u}\right)$, the $0.2 \%$ offset yield strength $\left(\sigma_{y}\right)$, and the strain to fracture $\left(\varepsilon_{f}\right)$.

The hardness values of all cast specimens were evaluated using a Digital Rockwell Hardness Tester. Prior to the test, the specimens were polished to obtain a smooth surface. A direct load of $584.9 \mathrm{MN}(60 \mathrm{~kg})$ was applied on the specimens and the hardness values were recorded. Multiple hardness tests were performed on each specimen and the average value was taken as the hardness of the specimen.

\section{Results And Discussion}

Table 1 shows the spectrometric analysis indicating the lean alloying chemistry in the selected 6063 aluminum.

Table 1: Chemical composition of 6063 aluminum alloy

\begin{tabular}{|l|l|l|l|l|l|}
\hline Element & \% Composition & Element & \% Composition & Element & \% Composition \\
\hline $\mathbf{S i}$ & 0.401 & $\mathbf{M g}$ & 0.501 & $\mathbf{C a}$ & 0.004 \\
\hline $\mathbf{F e}$ & 0.206 & $\mathbf{Z n}$ & 0.006 & $\mathbf{A l}$ & Bal. \\
\hline $\mathbf{C u}$ & 0.011 & $\mathbf{C r}$ & 0.003 & & \\
\hline $\mathbf{M n}$ & 0.013 & $\mathbf{T i}$ & 0.008 & & \\
\hline
\end{tabular}

\subsection{Micrograph}

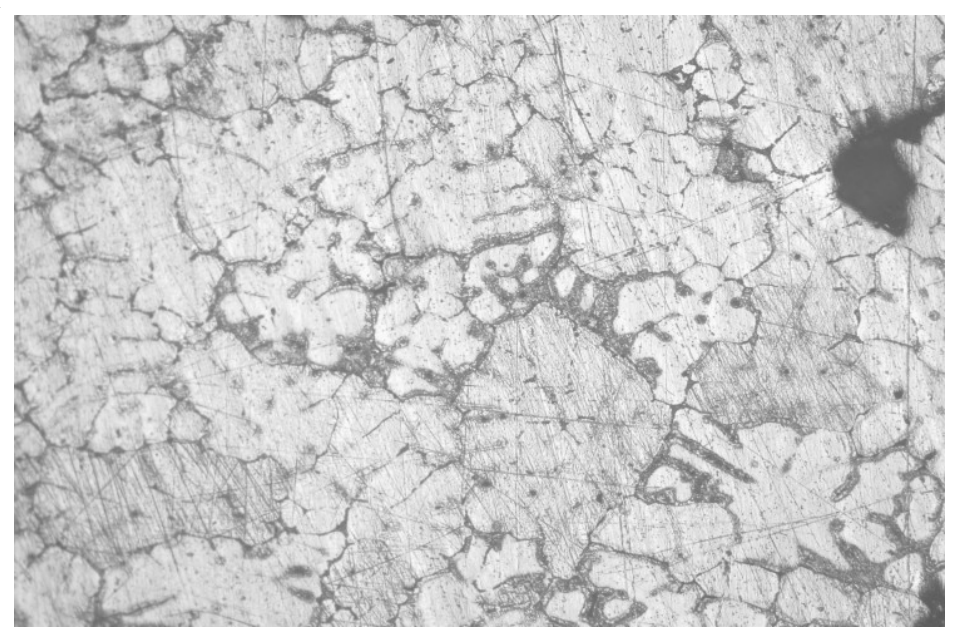

Figure 1: Micrograph of sample A (as cast) 6063 aluminium X100 


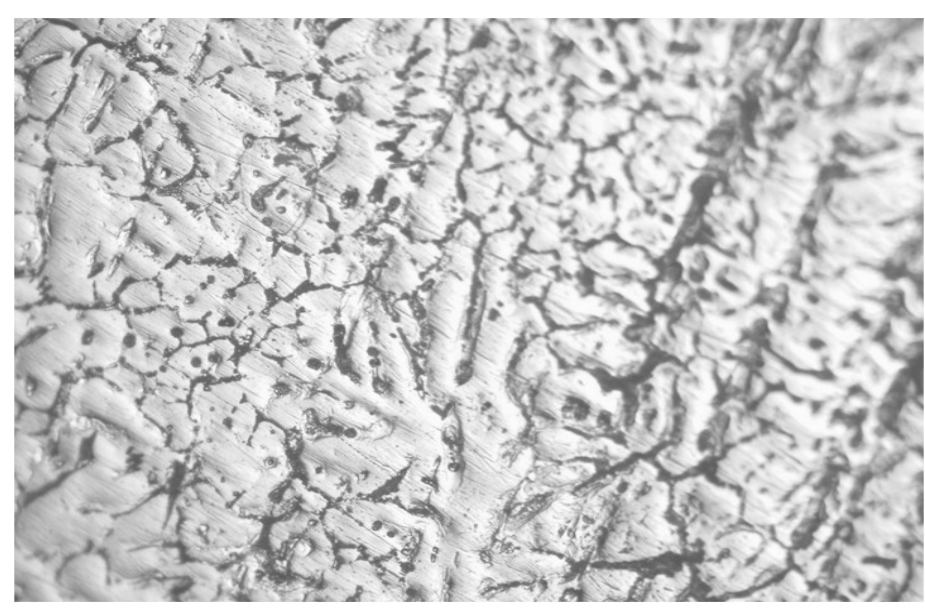

Figure 2: Micrograph of sample B (aluminium 6063 with 5\% HDPE) X100

Daheng software driven metallurgical microscope was used to view and capture the microstructures of the samples. From the photomicrograph, it was observed as shown in Figure 1 that the sample with 5\% HDPE have clear and continuous network of grain boundaries. The silicon strand is also visible and evenly distributed in the micrograph. The reason for this continuous network could be attribute to the high density of the polyethylene used in the experiment, thus resulting in the close-packed bond relationship among the grains. The HDPE added was seen to segregate along the grain boundaries thereby disorganizing the initial structure. The microstructure of sample B (Figure 2) however, shows thickened grain boundaries alongside cracks promoting discontinuity among the colonies.

\subsection{Hardness}

Table 1: Microhardness result of selected samples

\begin{tabular}{llllll}
\hline Label & I & II & III & IV & Average \\
\hline Sample A & 101.2 & 100.2 & 103.3 & 105.7 & 102.6 \\
Sample B & 112.9 & 108.1 & 115.1 & 115.6 & 112.93 \\
\hline
\end{tabular}

Four samples were selected for microhardness analysis at room temperature and the results are as shown in Table 2. From the table, it was observed that when a load of $584.9 \mathrm{MN}(60 \mathrm{~kg})$ was applied on the samples over a period of 10 seconds, sample B exhibited a high average hardness of $112.193 \mathrm{HV}$ while sample A recorded average hardness of $102.60 \mathrm{HV}$. The higher values recorded in sample B may be due to it thickened grain boundaries and the discontinuity in the microstructure.

\subsection{Tensile Results}

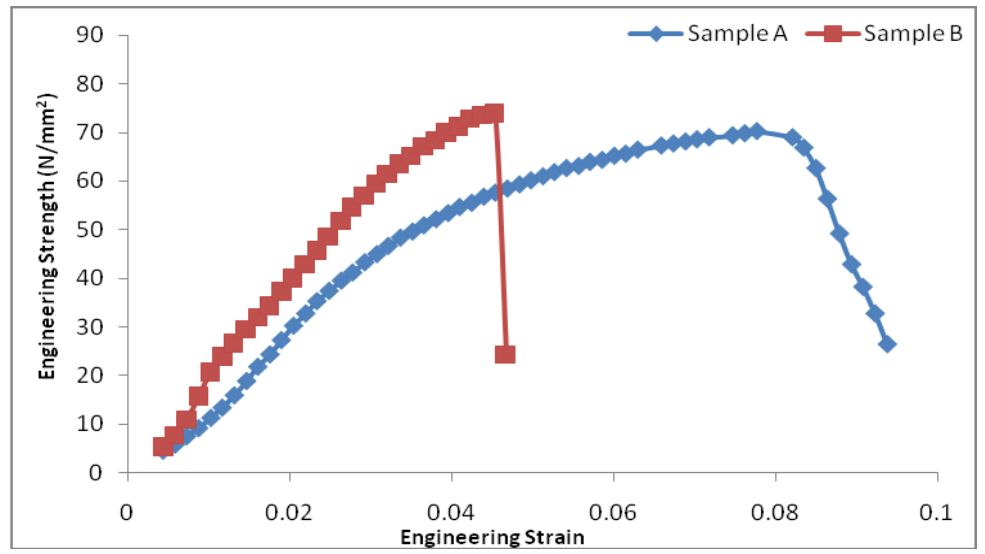

Figure 3: Variation of Strength to Strain at regular strain rate

Table 3: summary of tensile properties

\begin{tabular}{lllll}
\hline Label & Eng. UTS (N/mm & 0.2\% Proof & & \\
Strength & Peak Displacement (\%) & strain to fracture $(\%)$ \\
\hline Sample A & 70.2 & 57.6 & 7.77 & 9.67 \\
Sample B & 73.9 & 57.0 & 4.53 & 4.67 \\
\hline
\end{tabular}


A uniaxial tensile test was conducted using an electronic tensiometer at a regular strain rate. Figure 3 shows the super-imposed plots of the two samples, the results confirm that samples sample B (with 5\% HDPE) exhibited high ultimate tensile strength (UTS) in comparison with sample A which serves as the control in this experiment. The tensile plots show that the addition of HDPE into aluminum results in the significant improvement in the ultimate tensile strength (UTS) with a peak value of about $74.0 \mathrm{~N} / \mathrm{mm}^{2}$, the ductility of the material is however observed to have been reduced by about $42 \%$. This thus indicate that despite the remarkable increase in the hardness and strength of sample B (with 5\% HDPE), its failure under tensile loading is sudden when compare with the displacement exhibited in sample A.

\section{Conclusion}

In an attempt to study the effect of HDPE in Al matrix, the possibility of entrapping high density polyethylene (HDPE) in aluminum by casting without allowing vaporization of the HDPE is feasible.

In this experiment, microscope, microhardness tester and electronic tensiometer was used to characterize the cast. From the results, it was observed that when a high density polyethylene (HDPE) is entrapped in Al matrix, a positive and significant increment in the hardness and strength is enhanced, though at the expense of its ductility.

\section{References}

[1] M.F. Ashby and R.H. David (1992): Engineering Materials 2, with corrections (in English), Oxford: Pergamon Press. ISBN 0-08032532-7, pp. 201-209.

[2] S.L. Kakani and A. Kakani (2005): Material Science, pp. 216-221.

[3] K.G. Budinski and M.K. Budinski (2008): Engineering Materials Properties and selection, Pp.89.

[4] T. A. Khalifa and T. S. Mahmoud (2009): Elevated Temperature Mechanical Properties of Al alloy AA6063/SiC $\mathrm{p}$ MMCs, Proceedings of the World Congress on Engineering. Vol II WCE 2009, London, U.K, ISBN: pp 978 -988.

[5] G. Mrówka-Nowotnik and J. Sieniawski, (2005 ): "Influence of heat treatment on the microstructure and mechanical properties of 6005 and 6082 aluminium alloys," in Proceedings of the 13th Scientific International Conference on Achievements in Mechanical and Materials Engineering, pp. 447-450.

[6] G. Mrówka-Nowotnik and J. Sieniawski, (2005): "Influence of heat treatment on the microstructure and mechanical properties of 6005 and 6082 aluminium alloys," Journal of Materials Processing Technology, vol. 162-163, pp. 367-372.

[7] P. Orozco-Gonzàlez, M. Castro-Romàn, J. López-Rueda, (2011): "Effect of iron addition on the crystal structure of the $\alpha$ AlFeMnSi phase formed in the quaternary Al-Fe-Mn-Si system," Revista de Metalurgia, vol. 47, no. 6, pp. 453-461.

[8] D.E.Esezobor, S. O. Adeosun (2006): improvement on the strength of 6063 aluminum alloy by means of solution heat treatment. Conference on Materials Processing Challenges for the Aerospace Industry. Materials Science and Technology (MS\&T). Pp. $645-655$.

[9] K.K. Alaneme, B.O. Ademilua, M.O. Bodunrin (2013): Mechanical Properties and Corrosion Behaviour of Aluminium Hybrid Composites Reinforced with Silicon Carbide and Bamboo Leaf Ash. Tribology in Industry. Vol. 35, No. 1. Pp $25-35$

[10] K.V. Mahendra, A. Radhakrisna (2010): Characterization of stir cast Al-Cu-(fly ash + SiC) hybrid Metal Matrix Composites, Journal of Composite Materials, Vol. 44, No. 8, pp. 989-1005.

[11] H. Zuhailawati, P. Samayamutthirian, C.H. Mohd Haizu (2007): Fabrication of Low Cost Aluminium Matrix Composite Reinforced with Silica Sand, Journal of Physical Science, Vol. 18, No. 1, pp. 47-55.

[12] F.C.R. Hernandez, H.A. Calderon (2012): Nanostructured A1/Al4C3 composites reinforced with graphite or fullerene and manufactured by mechanical milling and spark plasma sintering, Materials Chemistry and Physics, Vol. 132, No. 2-3, pp. 815-822.

[13] K. Chrissafis, K. M. Paraskevopoulos, I. Tsiaoussis, and D. Bikiaris (2009): "Comparative study of the effect of different nanoparticles on the mechanical properties, permeability, and thermal degradation mechanism of HDPE," Journal of Applied Polymer Science, vol. 114, no. 3, pp. 1606-1618.

[14] M. Kontopoulou and L. C. Huang (2004): "Rheology, structure, and properties of ethylene-vinyl acetate/metallocene- catalyzed ethylene- $\alpha$-olefin copolymer blends," Journal of Applied Polymer Science, vol. 94, no. 3, pp. 881-889.

[15] A. M. Henderson (1993): "Ethylene-vinyl acetate (EVA) copolymers: a general review," IEEE Electrical Insulation Magazine, vol. 9, no. 1 , p. 30.

[16] A. Sharif, N. Mohammadi, and S. R. Ghaffarian (2008): "Practical work of crack growth and environmental stress cracking resistance of semicrystalline polymers," Journal of Applied Polymer Science, vol. 110, No. 5, pp. 2756-2762.

[17] Q. Dong, Q. Zheng, M. Du, and M. Zhang (2005): “Temperature dependence of dynamic rheological properties for high-density polyethylene filled with graphite," Journal of Materials Science, vol. 40, no. 13, pp. 3539-3541.

[18] Y. C. Li and G. H. Chen (2007): "HDPE/expanded graphite nanocomposites prepared via masterbatch process," Polymer Engineering and Science, vol. 47 , no. 6, pp. 882-888.

[19] C. Sun,W. Zhao, and S. Chen (2008): "Studies on the comprehensive performance of graphite and additives filled high density polyethylene composites," Journal of Applied Polymer Science, vol. 107, no. 6, pp. 4000-4004. 